\title{
DÜBLIN
}

Technological University Dublin

ARROW@TU Dublin

\section{Dual Frequency Dual Circularly-polarised Patch Antenna with Wide Beamwidth}

\author{
Xiulong Bao \\ Technological University Dublin, xiulong.bao@tudublin.ie \\ Max Ammann \\ Technological University Dublin, max.ammann@tudublin.ie
}

Follow this and additional works at: https://arrow.tudublin.ie/engschececon

Part of the Electrical and Computer Engineering Commons

\section{Recommended Citation}

Bao, X. \& Ammann, M. (2007) Dual frequency dual circularly-polarised patch antenna with wide beamwidth. IEEE Transactions on Antennas and Propagation,Vol.55, issue 6, part 2, pp.1760-1767. St.Petersburg, June 2007, doi:10.1109/TAP.2007.898575

This Conference Paper is brought to you for free and open access by the School of Electrical and Electronic Engineering at ARROW@TU Dublin. It has been accepted for inclusion in Conference papers by an authorized administrator of ARROW@TU Dublin. For more information, please contact arrow.admin@tudublin.ie, aisling.coyne@tudublin.ie,gerard.connolly@tudublin.ie. Funder: Science Foundation Ireland 


\section{Dual-frequency dual circularly-polarised patch antenna with wide beamwidth}

\section{X.L. Bao and M.J. Ammann}

A dual-frequency dual-circularly polarised patch antenna with wide beamwidth is proposed. The two-layer structure comprises circular patches with offset circular slots connected to rectangular slots. They provide orthogonal perturbations realising RHCP and LHCP for the lower and upper bands, respectively. The wide beamwidth is realised by extending the substrate beyond the groundplane. Measurements show a maximum beamwidth of $180^{\circ}$ and gains of 3.9 and $0.5 \mathrm{dBic}$ for zenith and $10^{\circ}$ elevation, respectively, for the upper band. The measured beamwidth for the low band is $130^{\circ}$ with a maximum gain of 3.9 and $-0.7 \mathrm{dBic}$ for zenith and $10^{\circ}$ elevation, respectively. The axial-ratio is less than $3 \mathrm{~dB}$ in the hemisphere for elevations greater than $10^{\circ}$ for both bands.

Introduction: Circularly-polarised microstrip patch antennas have been widely used in satellite navigation systems and GPS. Recently, many studies on circularly-polarised (CP) antennas have been reported, such as wideband $\mathrm{CP}$ antennas [1] and dual-frequency dual-CP antennas [2]. In [2] the microstrip-fed dual-sense dual-frequency operation was achieved in a single layer, whereas this proposed probe-fed antenna employs two layers and is less constrained, with a larger range of frequency-ratios attainable and wider beamwidth. Broad beamwidth antenna characteristics are very valuable in base station [3] and GPS [4] applications and can improve the coverage area in wireless communication systems. Typically, microstrip antennas provide a $3 \mathrm{~dB}$ beamwidth of $110^{\circ}$, and gain at $10^{\circ}$ elevation $\left(\theta=80^{\circ}\right)$ is $-3 \mathrm{dBic}$ Researchers have used many techniques to achieve broad beamwidth characteristics, such as an antenna with a pyramidal ground structure and a partially enclosed flat conductor wall achieving axial-ratio (AR) beamwidths greater than $130^{\circ}$ in two planes [4], a broad beamwidth patch antenna with auxiliary radiators yielding a $16 \%$ beamwidth broadening [5], a hybrid perturbation technique with stacked square-ring antennas [6] and extended dielectric substrate [7]. In this Letter, a wide beamwidth antenna is proposed for applications in telemetry and mobile satellite communications systems. The antenna comprises two circular patches fabricated on high permittivity dual-layer substrates. By extending the length of the substrate, the proposed dual-frequency dual-circularly polarised antenna can provide very wide beamwidth with an axial ratio of less than $3 \mathrm{~dB}$ over the entire hemisphere for both frequency bands.

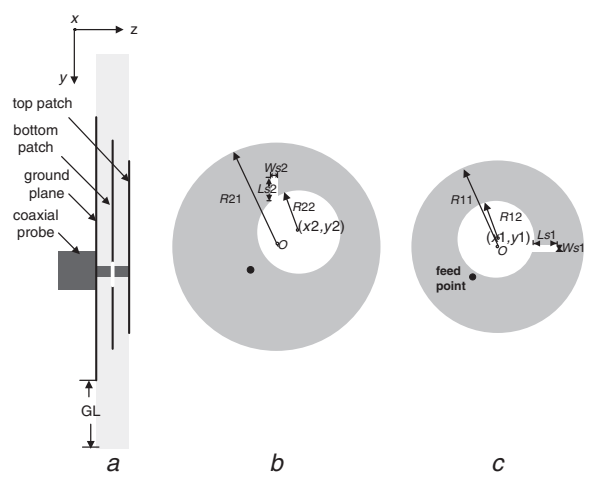

Fig. 1 Geometry of proposed dual-frequency dual-circularly polarised antenna

$a$ Substrate

$b$ Bottom patch

$c$ Top patch

Antenna dimensions and geometry: The configuration of the proposed antenna is shown in Fig. 1, which consists of a two-layer circular patch, each layer with an embedded circular-slot connected to a narrow rectangular slot. The rectangular slots are rotated by $90^{\circ}$ with respect to each other. The top patch is fed by a $50 \Omega$ coaxial probe. The slot combination provides the necessary perturbation and two orthogonal degenerate resonant modes with a $90^{\circ}$ phase difference, yielding CP characteristics. To achieve RHCP and LHCP characteristics simultaneously, two similar patches are placed on different layers. The circular slots in the top and bottom layers are offset (values in Table 1), which helps to provide good matching in the two different frequency bands.

Table 1: Dimensions of proposed antenna

\begin{tabular}{|c|c|c|c|c|c|c|c|c|c|c|c|}
\hline & \multicolumn{9}{|c|}{ Top Patch } & \multicolumn{5}{c|}{ Bottom Patch } & $\begin{array}{c}\text { Feed } \\
\text { point } \\
(\mathrm{mm})\end{array}$ \\
\cline { 2 - 11 } \\
$\begin{array}{c}\text { Parameters } \\
(\mathrm{mm})\end{array}$ & $R 11$ & $R 12$ & $L s 1$ & $W s 1$ & $\begin{array}{c}\text { Circular } \\
\text { slot } \\
\text { offset } \\
(x 1, y 1)\end{array}$ & $R 21$ & $R 22$ & $L s 2$ & $W s 2$ & $\begin{array}{c}\text { Circular } \\
\text { slot } \\
\text { offset } \\
(x 2, y 2)\end{array}$ & $(2.9,2.9)$ \\
\cline { 2 - 9 } & 13.0 & 3.2 & 5.3 & 0.8 & $(0,-1)$ & 18.0 & 4.1 & 0.8 & 3.4 & $(-4,-4)$ \\
\hline
\end{tabular}

The half-power beamwidth (HPBW) is heavily dependent on parameters such as the groundplane size and substrate materials. Usually, as the groundplane size decreases, the HPBW will increase for the same patch antenna, and a high permittivity substrate can also reduce the antenna size and groundplane size, so it can also help provide a wider HPBW. But the gain will decrease for these conditions. In this Letter, one method to enhance antenna gain under the same conditions (same patch and groundplane size) is to extend the length of substrate. By extending the substrate beyond the groundplane, the width of the radiation beam and gain will also be increased, yielding wide beamwidth with reasonably constant gain across the entire hemisphere. The selected parameters for the antenna are listed in Table 1. It is printed on a Taconic substrate with permittivity 9.5 , thickness $1.58 \mathrm{~mm}$ and loss tangent 0.0018 .

A parametric study of substrate extension length was made using the finite-integration time-domain solver (CST MWS) and the peak gain, beamwidth and gain at $10^{\circ}$ elevation is compared and shown in Table 2. It can be observed that the $3 \mathrm{~dB}$ beamwidth and gain at the $10^{\circ}$ elevation angle $\left(\theta=80^{\circ}\right)$ are increased as the length of the substrate extension is increased. For the low frequency at $1.450 \mathrm{GHz}$, the peak gains have increased by $3 \mathrm{~dB}$ as the length of substrate size is changed from 40 to $120 \mathrm{~mm}$, but in the high-frequency band at $2.010 \mathrm{GHz}$, the peak gains have decreased because of the significantly increased beamwidth.

Table 2: Performance comparison for difference substrate sizes

\begin{tabular}{|c|c|c|c|c|c|c|}
\hline \multicolumn{2}{|c|}{ Measured parameter } & $\begin{array}{c}\text { Substrate size } \\
40 \times 40 \mathrm{~mm} \\
\mathrm{GL}=0\end{array}$ & $\begin{array}{c}\text { Substrate } \\
\text { size } \\
60 \times 60 \mathrm{~mm} \\
\mathrm{GL}=10\end{array}$ & $\begin{array}{c}\text { Substrate } \\
\text { size } \\
80 \times 80 \mathrm{~mm} \\
\mathrm{GL}=20\end{array}$ & $\begin{array}{c}\begin{array}{c}\text { Substrate } \\
\text { size }\end{array} \\
100 \times 100 \mathrm{~mm} \\
\mathrm{GL}=30\end{array}$ & $\begin{array}{c}\text { Substrate } \\
\text { size } \\
120 \times \\
120 \mathrm{~mm} \\
\mathrm{GL}=40\end{array}$ \\
\hline \multirow{3}{*}{$\begin{array}{c}\text { Low } \\
\text { frequency } \\
1.450 \mathrm{GHz} \\
(x \mathrm{oz} \text { plane })\end{array}$} & $\begin{array}{c}3 \mathrm{~dB} \\
\text { beamwidth }\left(^{\circ}\right)\end{array}$ & 116 & 116 & 118 & 124 & 126 \\
\hline & $\begin{array}{c}10 \text { degree } \\
\text { elevation } \\
\text { gain }(\mathrm{dBic})\end{array}$ & -4.5 & -2.3 & -1.2 & -1.0 & -0.8 \\
\hline & $\begin{array}{c}\text { Peak } \\
\text { gain }(\mathrm{dBic}) \\
\end{array}$ & 1.1 & 2.5 & 3.1 & 3.6 & 4.1 \\
\hline \multirow{3}{*}{$\begin{array}{c}\text { High } \\
\text { frequency } \\
2.010 \mathrm{GHz} \\
(x \mathrm{oz} \text { Plane) }\end{array}$} & $\begin{array}{c}3 \mathrm{~dB} \\
\text { beamwidth }\left({ }^{\circ}\right)\end{array}$ & 100 & 110 & 140 & 170 & 190 \\
\hline & $\begin{array}{c}10 \text { degree } \\
\text { elevation } \\
\text { gain }(\mathrm{dBic})\end{array}$ & -2.5 & -2.0 & -0.8 & 0 & 0.8 \\
\hline & $\begin{array}{l}\text { Peak gain } \\
\text { (dBic) }\end{array}$ & 4.8 & 4.6 & 4.28 & 3.5 & 3.2 \\
\hline
\end{tabular}

Measured results: Based on the numerical results, the antenna was designed and fabricated. The substrate size is $100 \times 100 \mathrm{~mm}$ and ground plane size is $40 \times 40 \mathrm{~mm}$. RHCP and LHCP were realised for the lower and upper frequency, respectively. Fig. 2 shows the measured $S_{11}$. The frequency range for which the return loss is greater than $10 \mathrm{~dB}$ was found to be $1.431-1.464 \mathrm{GHz}(33 \mathrm{MHz})$ for low frequency and $2.001-2.063 \mathrm{GHz}(62 \mathrm{MHz})$ for the upper band. The measured result is in good agreement with the simulated results. Fig. 2 also illustrates that the $3 \mathrm{~dB}$ axial-ratio (AR) bandwidth is $9 \mathrm{MHz}(1.448-$ $1.457 \mathrm{GHz})$ and $14 \mathrm{MHz}(2.022-2.036 \mathrm{GHz})$ for the low and high bands, respectively. Measurements show that a wide beamwidth can be provided by the proposed antenna. It is shown in Fig. 3 that for the low band, the beamwidth is $130^{\circ}$ for the $x \mathrm{o} z$ plane and $100^{\circ}$ for the $y \mathrm{o} z$ plane; for the high band, the beamwidth is $180^{\circ}$ for the $x \mathrm{o} z$ plane and $114^{\circ}$ for the $y \mathrm{o} z$ plane. The $3 \mathrm{~dB}$ axial-ratio (AR) beamwidth is also improved for the two bands, as shown in Fig. 4. For the low band, the $3 \mathrm{~dB}$ AR beamwidth was found to be $182^{\circ}$ and $165^{\circ}$ in the $x \mathrm{O} z$ and $y \mathrm{o} z$ plane, respectively, and for high band, it was $184^{\circ}$ and 
$175^{\circ}$ in the $x \mathrm{o} z$ plane and $y_{\mathrm{o} z}$ planes, respectively. The measured maximum gain was found to be $3.9 \mathrm{dBic}$ for both bands.

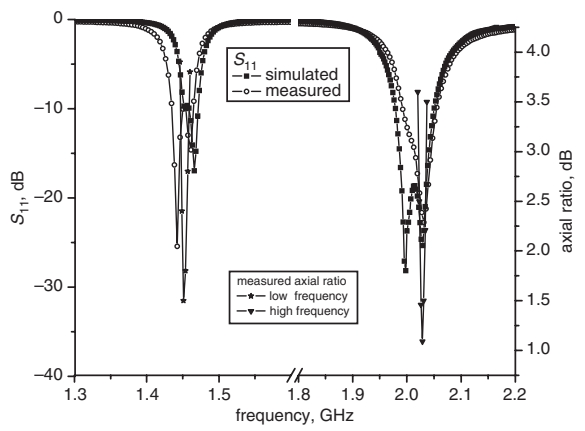

Fig. 2 Comparison of measured and simulated $S_{11}$ for proposed antenna and measured axial ratio
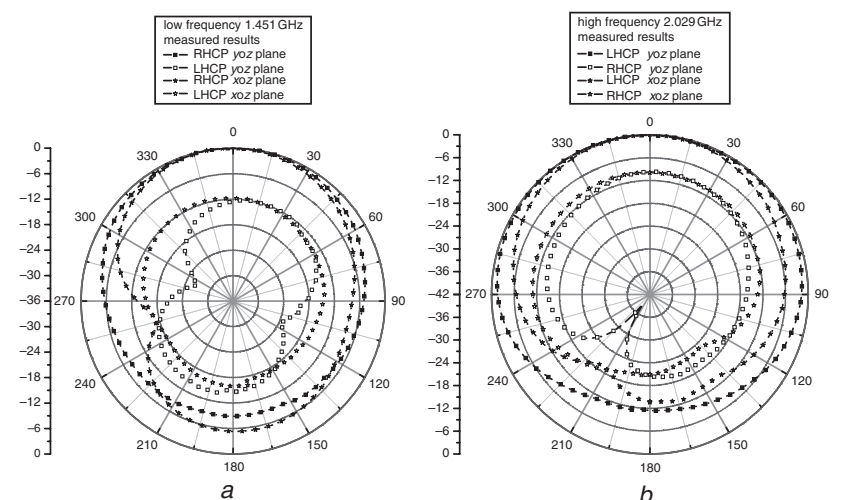

Fig. 3 Measured normalised radiation patterns

a $1.451 \mathrm{GHz}$

b $2.029 \mathrm{GHz}$

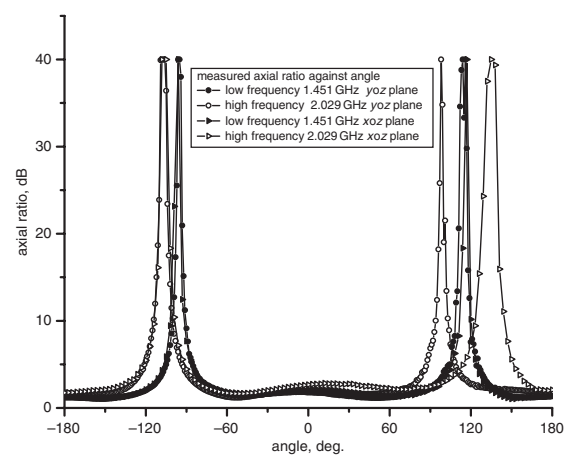

Fig. 4 Measured axial-ratio against angle at 1.451 and $2.029 \mathrm{GHz}$
Conclusions: A novel dual-frequency dual circularly-polarized antenna with broad beamwidth is presented. By using dual-layer patches with orthogonal and offset-centred slots, RHCP and LHCP characteristics are achieved, simultaneously. A broad beamwidth is realised using an extended substrate. The proposed antenna can achieve a HPBW of $180^{\circ}$ and $130^{\circ}$ for high frequency and low frequency, respectively. The measured $10^{\circ}$ elevation gains are $0.5 \mathrm{dBic}$ at $2.029 \mathrm{GHz}$ and $-0.7 \mathrm{dBic}$ at $1.451 \mathrm{GHz}$.

Acknowledgment: This work is supported by Science Foundation Ireland.

(C) The Institution of Engineering and Technology 2008

5 August 2008

Electronics Letters online no: 20082284

doi: 10.1049/el:20082284

X.L. Bao and M.J. Ammann (Centre for Telecommunications ValueChain Research, School of Electronic \& Communications Engineering, Dublin Institute of Technology, Kevin Street, Dublin 8, Ireland)

E-mail: max.ammann@dit.ie

\section{References}

1 Ferrero, F., Luxey, C., Jacquemod, G., and Starai, R.: 'Dual-band circularly polarized microstrip antenna for satellite applications', IEEE Antennas Wirel. Propag. Lett., 2005, 4, pp. 13-15

2 Bao, X.L., and Ammann, M.J.: 'Dual-frequency dual-sense circularlypolarized slot antenna fed by microstrip line', IEEE Trans. Antennas Propag., 2008, 56, (3), pp. 645-649

3 Kuai, Z.Q., Zhou, J.Y., and Hong, W.: 'A wide beam dual polarization and high gain antenna for WCDMA base station application'. Proc. IEEE APMC2005, 2005, Vol. 4, pp. 4-7

4 Su, C.W., Huang, S.K., and Lee, C.H.: 'CP microstrip antenna with wide beamwidth for GPS band application', Electron. Lett., 2007, 43, (20), pp. $1062-1063$

5 Chen, Z.N., Toh, W.K., and Qing, X.M.: 'A microstrip patch antenna with broadened beamwidth', Microw. Opt. Technol. Lett., 2008, 50, (7), pp. 1885-1888

6 Latif, S.I., and Shafai, L.: 'Hybrid Perturbation Scheme for Wide Angle Circular Polarisation of Stacked Square-Ring Microstrip Antenna', Electron. Lett., 2007, 43, (20), pp. 1065-1066

7 He, H.D.: 'A novel wide beam circular polarization antenna - microstripdielectric antenna'. Proc. Int. Conf. on Microwave and Millimeter Wave Technology, 2003, pp. 48-50 